\title{
1. Language and organization
}

\section{THE CENTRALITY OF LANGUAGE}

Can you imagine a human organization without a name? This simple thought experiment reveals how language and organization are intrinsically connected. Organizing implies the development and maintenance of regular patterns of interaction, and the conceptual and material activities involved in planning, acquiring resources, negotiating with internal and external stakeholders, coordinating action, etc. that constitute any contemporary organization, would not be possible in the absence of a sophisticated communication system. Any activity performed in a contemporary organization, be it a government agency, a corporate body, or a not for profit organization, demands the agency of language. In the absence of place names, signs, written policies, rules, procedures and a myriad of oral performances any organization would become effectively mute. It is only through linguistic construction that we can, individually and socially, make sense of the phenomena that we label 'organized activities'. While simple communicative interactions (expressing threats or friendliness, conveying elementary meaning, etc.) do not require a codified language to be performed, organized behaviour is founded on the use of a sophisticated sign system, allowing the transfer of articulated meanings.

The relationship between communication and language is not one of one-directional causation: as organizations are a product of language, so in the modern world language embeds organizations. A precondition for conceiving and understanding ideas that we consider commonplace, such as 'rule', 'money', 'market', 'sport', 'authority', is the tacit acknowledgement of a multiplicity of organizations. Taken-for-granted actions such as boarding a train, sitting in a lecture or attending an event imply the active participation of the subject in a complex network of organized actions involving a multitude of human and non-human agents (Latour 2005). Consequently the specific ways of organizing transactions of a given human society define the way in which we talk about and understand things. Even an apparently simple idea such as 'buying lunch' for a friend, could never be conceived by a member of a hunter-gatherer tribe, 
where commerce, market transactions, specialization of work do not exist. As language makes organizations possible so different organizational contexts attribute dissimilar meaning to words, including concepts that appear to be firmly grounded in our experience. For instance, the idea that something is 'urgent', or needs to happen 'immediately', can assume completely different connotations and bring about totally different behaviours, on a trading floor, in an accounting department or in a R\&D department.

In order to comprehend the nature of this relationship between language and organization we need to elucidate the meaning of these two entities. The problem is that there is quite a chasm between 'lay' and academic research-informed characterizations of organization and language. Dictionary definitions are a good starting point to determine general consensus, in the mundane sense, about concepts. According to the Oxford Dictionary of English an 'organization' is “an organized group of people with a particular purpose, such as a business or government department", whereas 'organized' means "arranged or structured in a systematic way" while 'language' is defined as "the system of spoken or written communication used by a particular country, people, community" (Oxford Dictionary of English 2011). These definitions privilege an essentialist view of the described objects and emphasize their instrumental functions: while such views are commonplace, they are problematic and they fail to incorporate a more nuanced and sophisticated understanding of these phenomena.

The traditional view of communication conceptualizes it as a linear transmission of contents from a sender to a receiver, using a coherent system of symbols which refer to objective phenomena. Contemporary organizational communication studies take a different perspective, looking at how the vocabulary in use shapes the reality of the situation, framing personal interaction (Ashcraft, Kuhn and Cooren 2009). Language is neither a discrete object made of utterances nor it is a representational instrument: it "is not only content; it is also context and a way to recontextualize content. We do not just report and describe with language; we also create with it" (Boje, Oswick and Ford 2004, p. 571).

Analogously, contemporary organizational scholarship rejects both reification and naïve teleological explanations of organizations. While the purposeful nature of organizations is not in doubt, their goals are contested and plural. Rather than providing a shared purpose, they act as sets of common constraints for individual actors (Simon 1964). More importantly, organizations are better understood as "islands of fabricated coherence in a sea of chaos and change" (Chia 2002, p. 866). Rather than stable objects, embodied in buildings and formal structures, they are a 
"momentary apprehension of an ongoing process of organizing" (Clegg, Kornberger and Rhodes 2005, p. 158). Their endurance is the outcome of a constant labour of re-production of routines, structures and relationships. A well-established stream of contemporary organization scholarship is indeed devoted to investigating how this 'organizing phenomena' produce and maintain the illusion of stability that we recognize as tangible and persistent institutional entities (see for instance Weick 1969 [1979]; Chia 2002; Tsoukas and Chia 2002; Clegg et al. 2005; Hernes 2007; Czarniawska 2008a, 2008b).

Shifting from a simplistic view of language and organization has fundamental implications for the notion of organizational discourse. Organizations are not just a stage for discourses, or their 'manufacturers', they are discursive products, kept together by rhetoric, narratives, speechacts. Equally, language is not a mere instrument used to convey those orders and instructions that are necessary for cooperation. For any form of collaborative action to occur actors need to develop a common understanding of their situation. As such, language empowers cooperation not just by exchanging information useful to coordinate action but also by producing a coherent model of meaning making, enabling individuals to build a common frame of reference. Words such as 'manager', 'meeting', 'incentive', 'process', 'promotion', 'policy', are not describing natural objects but they activate, make possible, organizational action and define expectations, roles and relationships.

Organizing is founded on a collective attribution of meaning, a "sense-making" process (Weick 1969 [1979], 1995) through which the multiple actors who participate in the organization share coherent processes to identify, describe, catalogue and interrelate their perceptions:

every perception is dependent on the conceptual apparatus which makes it possible and meaningful as this conceptual apparatus is inscribed in language. Talk and writing are thus much more than the means of expression of individual meanings: they connect each perception to a larger orientation and system of meaning. The conceptual distinctions in an organization are inscribed in the systems of speaking and writing. (Deetz 1982, p. 135)

The existence of these common patterns of meaning attribution is predicated on the existence of shared communicative codes. By labelling specific segments of our experience according to standardized conceptual descriptors we are separating and recombining in an intersubjectively intelligible picture an otherwise anarchical multiplicity of viewpoints. There is therefore a close interrelation between use of language and organizing. The ordering enacted in a given organization is as much a 
narrative and ideal reconstruction as a pragmatic arranging of words, bodies and actions towards an end (Rhodes 2001; Clegg et al. 2005). In Weick's word, organizing is "a consensually validated grammar for reducing equivocality by means of sensible interlocked behaviours" (1969 [1979], p. 3; emphasis added). This process involves selecting elements regarded as salient, ignoring others, clustering elements into discrete items and 'events', and attributing causal relationships (Weick 1969 [1979], pp. 148-9). Organizations are thus created and reproduced by linguistic means: discourses which articulate the flow of experience in a collectively meaningful and consistent picture. In this activity, material, performative ordering and cognitive sensemaking are mutually constitutive, since the former requires the latter for its execution. Both linguistic and organizational sensemaking thereby involve a process of mutual enactment through which they impose order on a more or less incoherent stream of random stimuli (Weick 1969 [1979]) that facilitates the emergence of practical objects and practices.

The intricate relationship between organizing and discourse will be the subject of Chapter 5; for the moment, it is important to clarify how language is not simply used to generate and convey meaning but also to 'order', in the dual meaning of 'arranging' and 'commanding'. A uniform, a workspace layout, a spreadsheet, contribute to articulate meaning and to offer a specific frame that regulates social behaviour through the explicit or implicit exercise of power. Deetz provides us with a vivid example:

the accountant's report invisibly creates the "visible" organization as a financial entity and provides a language for corporate self-understanding. Accounting is a disciplinary power that colonises the organization by creating newly internalized facts and vocabularies that are constitutive of organizational reality in a way that suppress potential conflict over its mission. (1992, p. 280)

What this author means is that by choosing to discuss an organization in terms of 'assets', 'liabilities', 'depreciation', 'cash flow', etc. and representing its complexity in simple mathematical figures a whole range of issues is silenced and interests ignored or treated as subordinate to financial outcomes. Even when the espoused intent of an accounting practice is that of safeguarding nature and society, as in the case of 'triple bottom-line', the attempt to capture the complex impact of a company on its environment in a single figure or to consider it in a short-term perspective produces spurious results (Norman and MacDonald 2004). The quantitatively based discourses of financial audit, quality control and 
risk management become therefore generative mechanisms that establish and legitimize the power of specific expert groups (Reed 2000, p. 529).

Using a discourse analysis perspective involves investigating three roles of language: the constitutive (of meaning), the productive (of identity) and the regulative (of behaviours). Rather than seeing these different outcomes of symbolic practice as 'functions' of language, which would convey an idea of agency and rational purpose, I prefer to define them as a consequence of our 'symbolic work'. An agent can use language strategically to pursue specific interests and goals (as happens for instance in the case of rhetorical statements); nonetheless, the disciplinary use of discursive elements is very often tacit. For instance, the accountants working for a university will certainly employ quantitative metrics to define and assess their organizational performances and in doing so they are actively supporting a managerialist view that privileges the commercial over the social role of academia, one that subordinates academic authority to bureaucratic direction (Parker and Jary 1995; Pfeffer and Fong 2004; Parker 2014). However, this behaviour is implicitly assumed as a 'normal' default way of performing their job, rather than a strategy instrumental to reinforcing their administrative power. The interpretive patterns are routine and applied unthinkingly (Luckmann 2008). Equally, the same academics who would have a vested interest in resisting the erosion of their professional autonomy actively participate in competitive benchmarking activities measuring their output by means of accounting measures, in accordance with the same discourse.

What emerges from these examples is the ambiguous separation between symbolic and material elements in any real setting. Tangible objects and concrete actions, even embodied, emotional reactions, are entangled with symbolic meanings; therefore symbolic practices are not merely representational but productive of meaning and action. Before investigating further the relationship between material and symbolic practices, we need to expand our understanding of the latter. To do so, I will devote the next section to a reflection on the attributes of language.

\section{LANGUAGE AND MEANING MAKING}

A fundamental set of questions regarding language concerns the topic of semantics, which covers two separate matters: first, understanding what is the meaning of this or that symbol for a particular group and, second, describing the set of conditions that have generated that meaning (Lewis 1970). Applied to the field of organizational studies this corresponds to two alternative research questions: to investigate what exactly a term, 
such as 'leadership' or 'strategic planning', refers to in different organizational settings; versus questioning why and how these different ways of constructing the notion of leadership or strategy have emerged in those contexts. Without entering into the complex and highly debated field of alternative theories of language and of semiotics it is useful to quickly outline the genealogy of the most widespread set of concepts currently informing the 'linguistic turn' in organizational studies.

Of foundational significance is the thought of de Saussure (1916 [1966]), who posited that words and symbols are mere signifiers - that is, totally arbitrary - that acquire meaning when combined with a mental image (a 'signified'). The notion of the whimsicality of language was not original: more than a century before, Fichte defined language as "the expression of our thoughts by means of arbitrary signs" (Fichte 1794 [1995], p. 120). The truly revolutionary value of the Saussurean lesson is to break completely with a "referential theory of meaning - i.e., the idea that language is a nomenclature which is in a one-to-one relation to objects" (Laclau and Mouffe 1987, p. 89), thus understanding language as a social phenomenon. Language is expressed in speech acts (parole) that are a concrete expression of an underlying system of differences, the language (langue); in terms of analogy, a specific game of chess is but one of the quasi-infinitely possible games that can emerge from the application of the rules of chess.

Even if one assumes that the purpose of verbal communication is to convey ideas and emotions faithfully, the relationship between signifier and signified is not just arbitrary but it is complicated by various factors. When pigeon-holed in word sequences, complex and fluid ideas are degraded, and any attempt to escape this verbal straightjacket by using linguistic or material tropes will have the consequence of emphasizing connotative meanings that exist only in the eye of the beholder. For instance the word 'family' has a very intelligible meaning for any English speaker; yet, any two individuals will probably append different connotations and references to the word, depending on their context and personal experience. To paraphrase Tolstoy, "all idealized families are alike; each experienced family is different in its own way".

The observation of this trade-off between clarity and comprehensibility led Bateson and Ruesch (1951, pp. 170-71) to describe two alternative coding modalities for human communication - digital and analogical. The former involves the type of arbitrary signification that Fichte mentions, for instance the use of the word 'sadness' to represent an emotion, while the latter entails representing an event in a socially recognizable way, using posture and gesture that convey that feeling, or evoking the emotion by means of metaphors or music. Analogical 
communication is easier to understand, because it "can be more readily referred to the thing it stands for" (Watzlawick, Jackson and Bavelas 1967 , p. 62) but this broad intelligibility comes at the expense of precision, exactness of meaning and economy of expression. For instance, while gesturing sadness comes easily to an accomplished actor or mime such as Marcel Marceau, one needs to resort to a digital language to argue the distinction between sadness and depression or their performance as theatre. The problem with these 'digital idioms' is that in the attempt to enhance accuracy and rigour they become esoteric and impenetrable for the uninitiated, so that the version of English language used by a British post-modern sociologist can be so different to that of an American economist as to render their texts mutually unintelligible. The range of 'digital languages' is at any rate enormous, since 'natural languages' and their idiomatic variations do not exhaust the possibilities of symbolic practice. Any symbolic system shared by a community, and which uses signs and rules to order it in order to communicate meaning, can be defined as a language, including mathematics, logic and musical notation, to name just a few. Therefore communication involves not only using language but also choosing among available languages, a choice that is often tacit but never unimportant or inconsequential.

The relationship between cognition, symbolic representation and communication has indeed been hotly debated by linguists, philosophers and psychologists. Divergent answers have been offered to questions on the innate or acquired structure of language, or on whether language determines our way of thinking. A substantial consensus has emerged, however, on the existence of a strong mutual relationship between language and production of meaning.

The gist of the matter is that "meaning [...] is not a quality inherent to certain experiences emerging within our stream of consciousness but the result of an interpretation of a past experience looked at from the present" (Schütz 1945, p. 535). Language enables knowledge in two manners: by offering a repository of these 'past experiences' that we use to interpret our present ones; and by expanding our possibilities of knowledge, surpassing the limits of our direct private experience to include "knowledge by description" (Russell 1912 [2004]).

Even if one accepts the position that sees language structures and grammars as (at least partially) innate and constitutive of the human mind, thus considering language as an "organ" (Chomsky 2000), the way in which language is used and performed remains culture and context specific. The importance of context can never be underestimated, not just because any interpretation of the text is context dependent but also because the same may be said of human rationality (Wittgenstein 1958). 
The idea of language as a repository of culturally specific experiences, interpretations and truths is connected to the notion of intertextuality, or how any text is a link in a chain of texts (Hardy 2001). This is an idea originally put forward by Kristeva (1980), who summarized and expanded the Saussurean idea that signs derive their meaning within the structure of the text, explaining how the meaning of a text is not directly and univocally transferred from a writer to a reader, but is mediated by the ideas that they both received from other texts. In other words, "all texts, whether they are spoken or written, make their meanings against the background of other texts and things that have been said on other occasions" (Paltridge 2012, p. 11). This sequence of references is what makes them intelligible, and recognizable, and constitutes a repository of "past interpretive acts that had been performed by innumerable other people, in short, a social stock of knowledge" (Luckmann 2008, p. 285).

The obvious question that emerges is then: to what extent a specific language, with its baggage of preconceived ideas, intertwined references, and idiosyncratic punctuation of infinitely nuanced phenomenological life-experience, constrains reasoning? The once-fashionable principle of linguistic determinism or Whorfian hypothesis (Whorf 1956 [1998]) predicates that the structure of a language determines (or at least influences) its speakers' cognition, a notion based on the observation of the characteristics of different linguistic communities. For instance, it was observed that a rich vocabulary to describe different types of snow enabled Inuit to perceive subtle differences in their environment that would be lost to a non-Inuit, and that the specific structure of tenses in Hopi language provided them with a peculiar notion of time. The validity of some of this empirical evidence has been contested (Malotki 1983; Pullum 1991), and more importantly the causal direction of the relation has been put in discussion: critics argue that it is not language that 'forces' individuals to think in specific terms but rather that specific contextual conditions determine the development of particular distinctions (Pinker 2008). Yet, differences in the languages used by different groups can make visible some historically developed cultural assumptions. As a matter of fact "the world can be conceptually partitioned in endless different ways" (Wetherell and Potter 1987, p. 25) as different languages are. For instance, in English a distinction is made between mutton and sheep, which has no parallel in French. Conversely, in Italian the difference between romantic love (amare) and friendly or parental affection (voler bene) is clearly articulated, whereas an English speaker would use the same expression 'I love you' for a partner or for a sibling. An examination of the Whorfian hypothesis in the perspective of cognitive psychology reaches the conclusion that different languages 
pose different challenges and opportunities for cognition, rather than determining them (Hunt and Agnoli 1991).

These differences in the performance of a language can enable speakers to sharpen their perception or at least their capacity to communicate subtle distinctions: for instance French speakers can more readily distinguish between different shades of brown having two terms (brun or marron) at their disposal. These differences can bring crucial capabilities, as demonstrated in the case of Guugu Yimithirr speakers. In their talk about location and motion these Indigenous Australians from Far North Queensland do not use their body as a point of reference (using left/right/front/back) but always refer to inflected forms of the four cardinal directions (north/south/east/west), which provides an exceptional ability to find their bearings (Haviland 1993; Levinson 1997). This does not necessarily imply linguistic determinism or that language determines cognition or social practice (since the opposite can be also be true) but rather that they influence each other. An example in point is offered by the perception of different types of (mild) medical conditions in different cultural contexts. Germans feeling dizzy and light-headed (i.e. having a funny turn) will describe their condition in much more serious terms as a 'circulatory collapse' (kreislaufkollaps); French speakers often complain of a circulatory condition known as 'heavy legs' (jambes lourdes), that is unknown outside France; Italians customarily attribute musculoskeletal aches to having been 'hit by air' (colpo d'aria) (Webb 2015). In each of these contexts these ailments are well recognized by laypeople and medical personnel alike and it is the existence of a specific terminology that enables the emergence of this intersubjective agreement and - most importantly - of a related set of diagnostic and preventative practices.

From this point of view, languages are sensemaking devices which provide their users with shared ways of 'punctuating' the stream of events into meaningful sequences and producing recognizable contexts (Bateson 1972, p. 166). As organizing tools, they enable individuals to position themselves in relation to events, consider their options, rank priorities, and identify problems and solutions. "Language does not 'simply' constitute reality, but also connects, frames and instructs" (Alvesson and Kärreman 2011, p. 1141). In sum, languages are not neutral vehicles for concepts. The difficulty of transmitting meanings in a social setting transcends the mere difficulties of 'diffusion', where the information spread by virtue of an intrinsic inertia is only opposed by resistance offered by the medium or by the receiver (Latour 1986). In order to convey ideas we need to translate them into a code, a process in which any translation is also a transformation, hence an alteration, of original meaning (Latour 2005). 
Dismissing the notion of language as reflecting an external independent reality and highlighting its role in the process of sensemaking leads to a form of linguistic idealism, the view according to which "what appears to us, or what we experience or what we are aware of, is a function of the language we use" (Rorty 1970, p. 116). This does not necessarily imply a radical form of constructionism, assuming that there is no objective reality independent from the observer:

The fact that every object is constituted as an object of discourse has nothing to do with whether there is a world external to thought, or with the realism/idealism opposition. An earthquake or the falling of a brick is an event that certainly exists, in the sense that it occurs here and now, independently of my will. But whether their specificity as objects is constructed in terms of "natural phenomena" or "expressions of the wrath of God", depends upon the structuring of a discursive field. What is denied is not that such objects exist externally to thought, but the rather different assertion that they could constitute themselves as objects outside any discursive condition of emergence. (Laclau and Mouffe 1985, p. 108)

This implies that language (and discourse) do not 'create' the world but make it meaningful (Cederström and Spicer 2014), which enables us to transcend the subject-object dualism, exploring how "experiences and objects are constituted in dialectical relationship to one another" (Mumby 2011, p. 1149). This idea can be explained by the case of the long search for a cure for scurvy. A potentially fatal degeneration of the connective tissues caused by a lack of vitamin C, scurvy became common among sailors during the Age of Sail, when it has been estimated that it killed more than two million sailors (Bown 2005). Ocean-crossing seamen were particularly affected by the disease because they had very limited access to fresh food, rich in vitamin C. In addition to human suffering, this 'occupational hazard' had important strategic consequences, limiting the operational capabilities of navies and affecting the wealth and capacity to project power for seafaring nations. Various empirical methods to stave off this hideous ailment - all based on the consumption of vitamin C-rich food - had been empirically discovered since the 16th century by a number of sailors and surgeons (Bown 2005). Nevertheless, all these effective remedies were overshadowed by other dubious, if not outright pernicious, 'cures' (including the swallowing of sulphuric acid or mercury) that appeared to be consistent with the dominant paradigm of Hippocratic medicine, according to which all illnesses stemmed from an imbalance in 'body fluids' or from noxious vapours. Lacking an appropriate conceptual (and linguistic) framework to distinguish scurvy from other ailments affecting mariners, to assess the validity of the 
claims of the many who insisted to have developed an effective remedy, but also to make sense of the therapy, understanding the reasons of its success, the medical establishment failed to acknowledge the empirical know-how of experienced sailors such as James Cook. "Scurvy could not be cured or prevented as long as it was not understood" (Bown 2005, p. 86), with the consequence that effective prophylactic measures were not implemented on a large scale by the navy until the 19th century.

Scurvy has a reality that transcends language: it can affect us equally regardless of whether we call it a 'grey killer' and attribute it to sloth or 'blocked spleens', or if we recognize it as a nutritional deficiency, where our body cannot produce collagen because of the lack of ascorbic acid. However the capacity to recognize its causes and to prevent and cure the disease is contingent on the availability of the development of a specific discursive apparatus. Other than clarifying the relationship between language and (perceived) reality, this example stresses the performative implications of language, indicating how our symbolic practices have a concrete impact on social action. The next section will explore this notion.

\section{LANGUAGE AND (SOCIAL) PERFORMANCES}

The 'ordering' work of language is not exclusively performed through an abstract process of meaning making, by which the available vocabulary and syntax shape our experience. Language has both an ostensive quality (ideal, conjectural, notional) and a performative quality (producing action, thinking and feeling) (Latour 1986), and language and society are intrinsically associated: "linguistic phenomena are social phenomena of a special sort, and social phenomena are (in part) linguistic phenomena. Linguistic phenomena are social in the sense that whenever people speak or listen or write or read they do so in ways which are determined socially and have social effects" (Fairclough 1989, p. 23).

There are various ways in which language is connected to action, becoming constitutive of social relationships. In the first place language can be used to negotiate the social relationship between the speaker and the audience, performing social tasks and achieving a phatic function (Malinowski 1923; Jakobson 1960), that is, acting as a 'social lubricant'. This form of communication, which includes courtesy formulas, etiquette, small talk, etc., conveys information about interlocutors' social identities with the intent of creating the conditions for an effective verbal exchange. The emphasis is on establishing and maintaining a relationship, rather than the content of what is said (Watzlawick et al. 1967). 
Moreover language can be used to bring about change, by expressing ideals and visions, appealing for support, setting rules or bargaining deals, performing a political function (Sillince 1999, pp. 488-90). Rhetorical uses of language are a case in point. Rhetoric is not just about persuading, it is also a means of identifying the self in relation to a particular issue, and of using that self-identification persuasively (Sillince 2005; Jarzabkowski, Sillince and Shaw 2010). In this regard rhetoric is both constructive of and constitutive of individual and organizational identity, being employed to resolve and retain the tension between different identities which are often at odds (Hartelius and Browning 2008). This role is performed especially by organizational rhetoric, which is usually directed at many different internal and external audiences, with the intent of projecting the desired organizational identity among many available ones (Sillince 2006).

It is however the interconnection between speech and action on which these social and political uses of language are predicated. The idea of the language as made of ostensive acts - that is, connecting words and objects by pointing to examples ('this is a cat') - is quite familiar but it is limited. Language is more than an ordered catalogue of symbols establishing an unambiguous semantic relationship between a sign and an object. As Wittgenstein $(1958, \S 38)$ points out "naming appears as a queer connexion of a word with an object", whereas "countless different kind[s] of use" are possible (Wittgenstein 1958, §23). Wittgenstein introduced the concept of "language-game" to highlight that "the speaking of a language is part of an activity, or of a form of life" (Wittgenstein $1958, \S 23)$. As a consequence, speech is interwoven with action, whereas "an utterance is itself an act" (Medina 2005, p. 13) structured by local rules and aimed at accomplishing a specific goal: a move in a language game. Through use of words life is injected in otherwise "dead" signs (Wittgenstein 1972, p. 4).

While action gives life to language, the opposite is also true, in a mutually constitutive relationship. Language also acts as a typifying medium for creating knowledge (Schütz 1953, p. 10), and the consequence of language games is thus the production of a "life-world" (Husserl 1935 [1965]), where the sedimentation of linguistic meaning and resources is used by social actors to structure the world into objects (Habermas 1984). Social reality is thus constructed through the use of a language that is, in turn, generated by social performances, in a recursive, iterative process.

Through the notion of language games it is possible to draw attention to the ways in which different communities use specialized forms of discourse to pursue their purposes and address various concerns (Astley 
and Zammuto 1992). The uses, or performances, that give life to language by fixing its meaning have both a normative dimension, specified by rules of intelligibility, as well as a contextual dimension that situates a concept within a particular environment that activates a context-specific meaning (Whiting 2010). Rather than conflating multiple meanings in an attempt to establish the 'correct' way of labelling a concept, the notion of language games accepts that actors can leverage various meanings of a term to accommodate the specific dynamics, interests and issues that characterize their contexts. Thus "to imagine a language means to imagine a form of life" (Wittgenstein 1958, §19).

For Wittgenstein $(1958, \S 85)$, the rules that characterize language games function as signposts providing direction, purpose and therefore meaning to action and understanding. These rules do not require enforcement by some external actor charged with their application. Rather their power is expressed implicitly, through acquired customs and taken-forgranted assumptions.

Organizational sensemaking, as a precondition for organized action (Weick 1969 [1979]), can therefore be seen as constituted by a series of interrelated language games, used to position, explain and justify actions and establish meaning. An effective demonstration of the way in which specific language games produce an organizational identity and culture, also defining "appropriate patterns of activity" (Astley and Zammuto 1992, p. 449), is offered by a classic study by Van Maanen:

Customers at Disneyland are, for instance, never referred to as such, they are "guests." There are no rides at Disneyland, only "attractions." Disneyland itself is a "Park," not an amusement center, and it is divided into "back-stage," "on-stage," and "staging" regions. Law enforcement personnel hired by the park are not policemen, but "security hosts." Employees do not wear uniforms but check out fresh "costumes" each working day from "wardrobe." And, of course, there are no accidents at Disneyland, only "incidents." (Van Maanen 1991, pp. 65-6)

Here the choice of terminology is not simply a marketing device but defines the identities of the employees and their relationship with other agents, and provides clear expectations about their performances and behaviours.

Consequently language is not a neutral medium but constitutes facts (Astley and Zammuto 1992, p. 445) thus becoming a source of identity. In this regard is possible to state that language is at the same time the instrument and the outcome of a process of social construction of reality, since it is on the one hand the essential vehicle for the social interaction that constitutes and maintains 'common-sense' knowledge (Berger and 
Luckmann 1967 [1990]) while, on the other hand, it reflects such social understandings.

As communication and language are constituted and maintained by performative acts, material elements also, such as the technologies in use, and the medium of communication, can play an active role in modelling the subjectivities of users and the ways in which they organize their activities and interactions. For instance, as mobile communication devices and portable computers have dramatically increased our capacity to 'stay connected', so the barrier between work and life has become increasingly permeable, making it customary for many of us to receive and send work-related communicatons at any hour of the day, irrespective of rest hours. In this case it is not the language but rather the medium which transforms organizing practices and shapes expectations and performances (McLuhan 1964 [1994]).

Despite the virtual impossibility of summarizing in a few pages the vast multidisciplinary debate on the philosophy, psychology and sociology of language, this brief (and unavoidably skewed) outline of the literature highlights some essential features that appear to characterize this bundle of complex phenomena.

- Language is instrumental to social action, as such it is the basis of any form of organization.

- Language is not merely representational but also interpretative, producing meaning.

- Language is plural: there are many possible modes of symbolic communication that can be either rigorous or broadly intelligible and that are grounded in different cultural contexts.

- Language is given consistency and coherence by communicative actions, and has an essential performative component.

The entanglement between action and communication and between social activities and sensemaking that characterize linguistic performances, together with the plurality of available idioms, suggest that it would be better to refer to symbolic practices rather than 'languages'. The concept of practice has been used in sociology and organizational studies to maintain that human actions are always situated, drawing meaning and substance from their embeddedness in a social and material network that they contribute to reproduce, thus overcoming dualisms between body and mind, individual and society, organism and environment (Bourdieu 1977, 1990; Gherardi 2000; Knorr-Cetina 2001; Savigny, Schatzki and Knorr-Cetina 2001; Raelin 2007; Corradi, Gherardi and Verzelloni 2010; Feldman and Orlikowski 2011; Gherardi 2012). Practices incorporate 
both explicit and 'tacit knowledge' (Polanyi 1966); they are "inscribed in bodies, and bodies are therefore the artefacts through which people know and work" (Gherardi 2012, p. 61); they include material objects ("the tools of the trade'); they are inscribed in, and enabled by, an institutional system (Gherardi 2006, p. 35); they include routines and improvisation.

The term discourse is therefore used to account for how particular symbolic practices (constituted of narratives, ways of talking, media, contexts, institutions, etc.) implicitly enable and foster specific patterns of meaning and action and influence our way of thinking and feeling; for instance, how prevalent ways of representing organizational leadership or discussing employment relationships, subtly define expectations, benchmarks and identities.

In this sense, discourse can be seen as an "interpretive repertoire" of social practices situated in a specific context, based on the use of linguistic elements but oriented to action (Potter et al. 1990). In the next chapter this concept will be 'unpacked', accounting for the many different notions of discourse that have been developed in social studies and that find application in the study of organizations.

\section{REFERENCES}

Alvesson, M. and Kärreman, D. 2011, 'Decolonializing Discourse: Critical Reflections on Organizational Discourse Analysis', Human Relations, vol. 64, pp. 1121-46.

Ashcraft, K.L., Kuhn, T.R. and Cooren, F. 2009, 'Constitutional Amendments: "Materializing" Organizational Communication', The Academy of Management Annals, vol. 3, no. 1, pp. 1-64.

Astley, W.G. and Zammuto, R.F. 1992, 'Organization Science, Managers, and Language Games’, Organization Science, vol. 3, pp. 443-60.

Bateson, G. 1972, Steps to an Ecology of Mind: Collected Essays in Anthropology, Psychiatry, Evolution, and Epistemology, Intertext, Aylesbury.

Bateson, G. and Ruesch, J. 1951, Communication, the Social Matrix of Psychiatry, Norton, New York.

Berger, P.L. and Luckmann, T. 1967 [1990], The Social Construction of Reality: A Treatise in the Sociology of Knowledge, Anchor Books, New York.

Boje, D.M., Oswick, C. and Ford, J.D. 2004, 'Language and Organization: The Doing of Discourse', Academy of Management Review, vol. 29, no. 4, pp. 571-7.

Bourdieu, P. 1977, Outline of a Theory of Practice, trans. R. Nice, Cambridge University Press, Cambridge.

Bourdieu, P. 1990, The Logic of Practice, Basil Blackwell, Cambridge.

Bown, S.R. 2005, Scurvy: How a Surgeon, a Mariner, and a Gentlemen Solved the Greatest Medical Mystery of the Age of Sail, St. Martin's Press, New York. 
Cederström, C. and Spicer, A. 2014, 'Discourse of the Real Kind: A Postfoundational Approach to Organizational Discourse Analysis', Organization, vol. 21, no. 2, pp. 178-205.

Chia, R. 2002, 'Essai: Time, Duration and Simultaneity: Rethinking Process and Change in Organizational Analysis', Organization Studies, vol. 23, pp. 863-8.

Chomsky, N. 2000, 'New Horizons in the Study of Language and Mind', in A. Arnove (ed.), The Essential Chomsky, Palgrave Macmillan, New York, pp. 285-99.

Clegg, S.R., Kornberger, M. and Rhodes, C. 2005, 'Learning/Becoming/ Organizing', Organization, vol. 12, pp. 147-67.

Corradi, G., Gherardi, S. and Verzelloni, L. 2010, 'Through the Practice Lens: Where is the Bandwagon of Practice-based Studies Heading?', Management Learning, vol. 41, pp. 265-83.

Czarniawska, B. 2008a, 'Organizations as Obstacles to Organizing', paper presented to the Nobel Symposium Foundations of Organization, 28-30 August, 2008, Stockholm, accessed 1 March 2012 at http://bit.ly/Zo2fcx

Czarniawska, B. 2008b, 'Organizing: How to Study it and How to Write about it', Qualitative Research in Organizations and Management: An International Journal, vol. 3, pp. 4-20.

de Saussure, F. 1916 [1966], Course in General Linguistics, McGraw-Hill, New York.

Deetz, S.A. 1982, 'Critical Interpretive Research in Organizational Communication', Western Journal of Speech Communication, vol. 46, pp. 131-49.

Deetz, S.A. 1992, Democracy in an Age of Corporate Colonization: Developments in Communication and the Politics of Everyday Life, SUNY Press, New York.

Fairclough, N. 1989, Language and Power, Longman, New York.

Feldman, M.S. and Orlikowski, W.J. 2011, 'Theorizing Practice and Practicing Theory', Organization Science, vol. 22, pp. 1240-53.

Fichte, J.G. 1794 [1995], 'On the Linguistic Capacity and the Origin of Language', in J.P. Surber (ed.), Language and German Idealism: Fichte's Linguistic Philosophy, Humanities Press, Adantic Highlands, NJ, pp. 117-44.

Gherardi, S. 2000, 'Practice-based Theorizing on Learning and Knowing in Organizations', Organization, vol. 7, pp. 211-23.

Gherardi, S. 2006, Organizational Knowledge: The Texture of Workplace Learning, Blackwell, London.

Gherardi, S. 2012, How to Conduct a Practice-based Study: Problems and Methods, Edward Elgar Publishing, Cheltenham, UK and Northampton, MA, USA.

Habermas, J. 1984, The Theory of Communicative Action, Beacon Press, Boston, MA.

Hardy, C. 2001, 'Researching Organizational Discourse', International Studies of Management \& Organization, vol. 31, p. 25.

Hartelius, E.J. and Browning, L.D. 2008, 'The Application of Rhetorical Theory in Managerial Research', Management Communication Quarterly, vol. 22, no. 1, pp. 13-39.

Haviland, J.B. 1993, 'Anchoring, Iconicity, and Orientation in Guugu Yimithirr Pointing Gestures', Journal of Linguistic Anthropology, vol. 3, no. 1, pp. 3-45. 
Hernes, T. 2007, Understanding Organization as Process: Theory for a Tangled World, Routledge, London.

Hunt, E. and Agnoli, F. 1991, 'The Whorfian Hypothesis: A Cognitive Psychology Perspective', Psychological Review, vol. 98, no. 3, p. 377.

Husserl, E. 1935 [1965], The Crisis of European Sciences and Transcendental Phenomenology: An Introduction to Phenomenological Philosophy, trans. Q. Lauer, Harper \& Row, New York.

Jakobson, R. 1960, 'Linguistics and Poetics', in T.A. Sebeok (ed.), Style in Language, The MIT Press, Cambridge, MA, pp. 350-77.

Jarzabkowski, P., Sillince, J.A.A. and Shaw, D. 2010, 'Strategic Ambiguity as a Rhetorical Resource for Enabling Multiple Interests', Human Relations, vol. 63, pp. 219-48.

Knorr-Cetina, K. 2001, 'Objectual Practice', in E.V. Savigny, T.R. Schatzki and K. Knorr-Cetina (eds), The Practice Turn in Contemporary Theory, Routledge, New York, pp. 184-97.

Kristeva, J. 1980, Desire in Language: A Semiotic Approach to Literature and Art, Basil Blackwell, Oxford.

Laclau, E. and Mouffe, C. 1985, Hegemony and Socialist Strategy: Towards a Radical Democratic Politics, Verso, London.

Laclau, E. and Mouffe, C. 1987, 'Post-Marxism Without Apologies', New Left Review, no. 166, p. 79.

Latour, B. 1986, 'The Powers of Association', in J. Law (ed.), Power, Action and Belief, Routledge and Kegan Paul, London, pp. 264-80.

Latour, B. 2005, Reassembling the Social: An Introduction to Actor-Network Theory, Clarendon, Oxford, UK.

Levinson, S.C. 1997, 'Language and Cognition: The Cognitive Consequences of Spatial Description in Guugu Yimithirr', Journal of Linguistic Anthropology, vol. 7 , no. 1 , pp. $98-131$.

Lewis, D. 1970, 'General Semantics', Synthese, vol. 22, no. 1, pp. 18-67.

Luckmann, T. 2008, 'On Social Interaction and the Communicative Construction of Personal Identity, Knowledge and Reality', Organization Studies, vol. 29, no. 2, pp. 277-90.

Malinowski, B.K. 1923, 'The Problem of Meaning in Primitive Languages', in C.K. Ogden and I.A. Richards (eds), The Meaning of Meaning. A Study of the Influence of Language upon Thought and of the Science of Symbolism, Harcourt, Brace \& Company, New York, pp. 451-510.

Malotki, E. 1983, Hopi Time: A Linguistic Analysis of the Temporal Concepts in the Hopi Language, Walter de Gruyter, Berlin.

McLuhan, M. 1964 [1994], Understanding Media: The Extensions of Man, The MIT Press, Boston, MA.

Medina, J. 2005, Language: Key Concepts in Philosophy, Continuum Books, London.

Mumby, D.K. 2011, 'What's Cooking in Organizational Discourse Studies? A Response to Alvesson and Kärreman', Human Relations, vol. 64, pp. 1147-61.

Norman, W. and MacDonald, C. 2004, 'Getting to the Bottom of "Triple Bottom Line"”, Business Ethics Quarterly, vol. 14, no. 2, pp. 243-62.

Oxford Dictionary of English 2011, 3rd edn, Oxford University Press, Oxford. 
Paltridge, B. 2012, Discourse Analysis: An Introduction, Bloomsbury Publishing, London.

Parker, M. 2014, 'University, Ltd: Changing a Business School', Organization, vol. 21, no. 2, pp. 281-92.

Parker, M. and Jary, D. 1995, 'The McUniversity: Organization, Management and Academic Subjectivity', Organization, vol. 2, pp. 319-38.

Pfeffer, J. and Fong, C.T. 2004, 'The Business School "Business": Some Lessons from the US Experience', Journal of Management Studies, vol. 41, pp. 150120.

Pinker, S. 2008, The Stuff of Thought: Language as a Window into Human Nature, Penguin, London.

Polanyi, M. 1966, The Tacit Dimension, Routledge \& Kegan Paul, London.

Potter, J., Wetherell, M., Gill, R. and Edwards, D. 1990, 'Discourse: Noun, Verb or Social Practice?', Philosophical Psychology, vol. 3, no. 2-3, pp. 205-17.

Pullum, G.K. 1991, The Great Eskimo Vocabulary Hoax and Other Irreverent Essays on the Study of Language, University of Chicago Press, Chicago.

Raelin, J.A. 2007, 'Toward an Epistemology of Practice', Academy of Management Learning \& Education, vol. 6, p. 495.

Reed, M. 2000, 'The Limits of Discourse Analysis in Organizational Analysis', Organization, vol. 7, no. 3, pp. 524-30.

Rhodes, C. 2001, Writing Organization: (Re)Presentation and Control in Narratives at Work, vol. 7, John Benjamins Publishing, Amsterdam, NL.

Rorty, R. 1970, 'In Defense of Eliminative Materialism', The Review of Metaphysics, pp. 112-21.

Russell, B. 1912 [2004], The Problems of Philosophy, Project Gutenberg Literary Archive Foundation, Salt Lake City, UT.

Savigny, E.v., Schatzki, T.R. and Knorr-Cetina, K. 2001, The Practice Turn in Contemporary Theory, Routledge, New York.

Schütz, A. 1945, 'On Multiple Realities', Philosophy and Phenomenological Research, vol. 5, pp. 533-76.

Schütz, A. 1953, 'Common-Sense and Scientific Interpretation of Human Action', Philosophy and Phenomenological Research, vol. 14, pp. 1-38.

Sillince, J.A.A. 1999, 'The Role of Political Language Forms and Language Coherence in the Organizational Change Process', Organization Studies, vol. 20, pp. 485-518.

Sillince, J.A.A. 2005, 'A Contingency Theory of Rhetorical Congruence', The Academy of Management Review, vol. 30, pp. 608-21.

Sillince, J.A.A. 2006, 'Resources and Organizational Identities: The Role of Rhetoric in the Creation of Competitive Advantage', Management Communication Quarterly, vol. 20, pp. 186-212.

Simon, H.A. 1964, 'On the Concept of Organizational Goal', Administrative Science Quarterly, vol. 9, pp. 1-22.

Tsoukas, H. and Chia, R. 2002, 'On Organizational Becoming: Rethinking Organizational Change', Organization Science, vol. 13, pp. 567-82.

Van Maanen, J. 1991, 'The Smile Factory: Work at Disneyland', in P. Frost, L. Moore, M. Louise, C. Lundberg and J. Martin (eds), Refraining Organizational Culture, SAGE, Newbury Park, CA, pp. 58-76. 
Watzlawick, P., Jackson, D.D. and Bavelas, J.B. 1967, Pragmatics of Human Communication: A Study of Interactional Patterns, Pathologies, and Paradoxes, Norton, New York.

Webb, R. 2015, 'You Are What You Speak: How Your Mother Tongue Shapes You', New Scientist, 15 December 2015, accessed at https://goo.gl/EUVPjJ

Weick, K.E. 1969 [1979], The Social Psychology of Organizing, 2nd edn, Addison-Wesley, Reading, MA.

Weick, K.E. 1995, Sensemaking in Organizations, SAGE Publications, Thousand Oaks, CA.

Wetherell, M. and Potter, J. 1987, Discourse and Social Psychology: Beyond Attitudes and Behaviour, SAGE Publications, Newbury Park, CA.

Whiting, D. 2010, 'Introduction', in D. Whiting (ed.), The Later Wittgenstein on Language, Palgrave-Macmillan, New York.

Whorf, B.L. 1956 [1998], Language, Thought, and Reality: Selected Writings of Benjamin Lee Whorf, The MIT Press, Cambridge, MA.

Wittgenstein, L. 1958, Philosophical Investigations, trans. G.E.M. Anscombe, Blackwell, Oxford.

Wittgenstein, L. 1972, The Blue and Brown Books - Preliminary Studies for the Philosophical Investigation, 2nd edn, Blackwell, Oxford. 